\title{
EFEITOS BACTERIOSTÁTICOS E BACTERICIDA DE ANTIBIÓTICOS SOBRE AS LISTERIA spp ISOLADAS EM GOIÂNIA DE PACIENTES COM CLÍNICA DE ABORTO REPETITIVO.
}

\author{
Idalina Thiomi Inumaru Nojimoto , Alberto José Centeno",

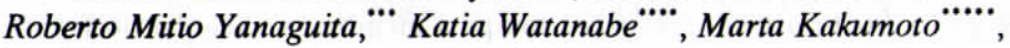 \\ Rosevaldo Miranda Machado
}

\section{RESUMO}

Neste estudo foi verificado a susceptibilidade "in vitro" aos antimicrobianos de Listeria spp isolados de endocervix de mulheres com clínica de aborto repetitivo. $O$ tratamento de listeriose com antibióticos mais freqüentemente recomendados (penicilina e ampicilina) sảo geralmente bem sucedidos, porém há vários casos notificados de falhas terapêuticas. Foi utilizado o método de macrodiluiçāo em tubo para determinar as concentraçōes mínimas inibitórias (MICs) e as concentraçōes mínimas bactericidas (MBCs). A ampicilina e a penicilina foram bacteriostáticas para as Listeria spp. A gentamicina e a ciprofloxacina foram bactericidas onde MBCs foram até 3 vezes maiores que as respectivas CMIs. Por outro lado as CMBs de penicilina e ampicilina foram pelo menos 6 vezes maiores que CMls. Três amostras de Listeria monocytogenes mostraram tolerância para com penicilina e ampicilina.

UNITERMOS: Antibióticos, Macrodiluição, Listeria spp, Aborto repetitivo

- Departamento de Microbiologia, Instituto de Patologia Tropical e Saúde Pública, Universidade Federal de Goiás.

“-Departamento de Biologia Celular, Instituto de Ciências Biológicas, Universidade Federal de Goiás

-.. Departamento de Microbiologia, Instituto de Ciências Biomédicas, Universidade de São Paulo

Bolsista de Iniciação científica $\mathrm{CNPq} / \mathrm{UFG}$

.... Departamento de Estatística, Instituto de Matemática e Física, Universidade Federal de Goiás - Recebido para publicação em 17/03/94 
NOIMOTOIT I:CENTENO A.J:YANAGUITA RM:WATANABE K K KAKUMOTO,M:MACHA DO,R.M. Efeitos bacteriostáticos e bactericida de antibióticos sobre as Listeria spp isoladas em Goiânia de pacientes com clínica de aborto repetitivo. Rev.Pat.Trop. 23(1):45-59, jan.jun.1994

\section{INTRODUÇÃO}

As espécies pertencentes ao gênero Listeria, distribuem-se de forma ubíqua e têm produzido severas infecções no hospedeiro humano tais como abortos meningites e septicemias (4). A eficácia terapêutica do tratamento antimicrobiano à listeriose humana é contudo limitado, pois aproximadamente $30 \%$ de pacientes sucumbem com esta infecção (8). Uma das razôes para explicar a baixa eficácia "in vivo" é o habitat intracelular de Listeria monocytogenes. A microscopia eletrônica registra que a Listeria monocytogenes rompe a membrana vacuolar do fagossomo e multiplica livremente no citosol (2).

Vários antibióticos têm sido sugeridos para o tratamento, sendo os mais freqüentemente usados as Penicilinas (3), Ampicilina (7) e Tetraciclina (4). Infelizmente, tem sido reportado falhas terapêuticas com o uso destes antibióticos $(3,4,6,7,9)$. A Tetraciclina é essencialmente bacteriostática e a Penicilina e Ampicilina são antibióticos bactericidas contra muitos microrganismos gram-positivos,porém são apenas bacteriostáticos contra Listeria monocytogenes (9). A falta de uma ação bactericida efetiva é uma desvantagem em potencial porque muitas infecções por Listeria ocorrem em pessoas com mecanismos de defesas imunocomprometidas (9).

O presente estudo foi realizado para explorar "in vitro", a possibilidade de se encontrar antibióticos de ação bactericida, oferecendo assim subsídios para o tratamento de infecções por Listeria, particularmente em pacientes imunocomprometidos.

Adicionalmente, em vista do fenômeno de tolerância presenciado em isolados de espécies (11), deseja-se examinar se ocorre tolerância com as cepas de Listeria isoladas em Goiânia.

\section{MATERIAL E MÉTODOS}

1. Cepas bacterianas. Foram estudadas 9 cepas de Listeria spp isoladas em Goiânia de secreção endocervical e de produtos de aborto, de gestantes com clínica de aborto repetitivo. Todas as cepas foram isoladas e identificadas por critérios padrōes de cultura, análises bioquímicas e asseguradas pela sorotipagem (3). Foram testadas simultaneamente, como cepas controles, Staphylococcus aureus (ATCC 25923), Pseudomonas aeruginosa (ATCC 25853), Escherichia coli (ATCC 25922) e Listeria monocytogenes (Scott A) de padrão de susceptibilidade já conhecida.
NOJIMOTO,I.T.I.;CENTENO,A.J.;YANAGUITA,R.M.;WATANABE,K.;KAKUMOTO,M.;MACHADO,R.M. Efeitos bacteriostáticos e bactericida de antibióticos sobre as Listeria spp isoladas em Goiânia de pacientes com clínica de aborto repetitivo. Rev.Pat.Trop. 23(1):45-59, jan./jun.1994.

2. Agentes antimicrobianos. Foram testados 4 agentes antimicrobianos: Penicilina, Ampicilina, Gentamicina e Ciprofloxacina. Todos os antibióticos foram dissolvidos em água destilada e estocados a $-20^{\circ} \mathrm{C}$ em volumes de $2 \mathrm{ml}$. Todas as diluições subseqüentes foram realizadas em Caldo de Tripticaseina Soja (TSB).

3. Preparo de inóculo bacteriano. Uma quantidade 3-5 colônias crescidas no Ágar Tripticaseina Soja (TSA) foram suspensas em $5 \mathrm{ml}$ de TSB e incubadas a $35^{\circ} \mathrm{C}$ por 3 a 4 horas para alcançar uma densidade óptica (D.O.) de 0,3 a 0,4 a 540 $\mathrm{nm}$ (espectro-fotômetro modelo 710 - Bausch \& Lomb). A viabilidade das células e a quantidade do inóculo foi também assegurada pela contagem de colônias após 24 horas a $35^{\circ} \mathrm{C}$ no TSA.

4. Determinação da Concentração Mínima Inibitória (CMI) e da Concentração Mínima Bactericida (CMB).

CMIs e as CMBs foram determinadas pela técnica de macrodiluição em tubo (15). Diluições seriadas dos antibióticos foram feitos em TSB variando de 0,01 - 200ug/ml.

A CMI qualitativa ou visual foi detectada como a menor concentração do antibiótico que inibiu o crescimento de multiplicação bacteriana, após incubação de 24 horas a $35^{\circ} \mathrm{C}(6)$.

A CMI quantitativa foi determinada recultivando em TSA volume de $0,1 \mathrm{ml}$ de cada tubo onde não ocorreu crescimento visível após incubação de 24 horas a $35^{\circ} \mathrm{C}$.

A CMB foi definida como a menor concentração do antibiótico que reduziu o inóculo inicial para $99,9 \%$ após 24 horas a $35^{\circ} \mathrm{C}(6)$. E para calcular $0,1 \%$ de bactérias sobreviventes, foi recultivado um volume de $0,1 \mathrm{ml}$ de cada tubo, onde não ocorreu crescimento visível e semeado no TSA e quantificados após 24 horas a $35^{\circ} \mathrm{C}$.

$\mathrm{O}$ critério de tolerância foi admitido quando a razão $\mathrm{CMB} / \mathrm{CMI}$ foi maior que $32(10,11)$.

\section{RESULTADOS}

A Ampicilina $(\leq 2,0 \mathrm{ug} / \mathrm{ml})$ foi eficiente contra todas as Listeria spp variando as CMIs quantitativas de 0,4-2,0 ug/ml. (Tabela 3, Gráfico 3). 
NOJIMOTO,I.T.I.;CENTENO,A.J.;YANAGUITA.R.M.:WATANABE.K.;KAKUMOTO,M.;MACHADO,R.M. Efeitos bacteriostáticos e bactericida de antibióticos sobre as Listeria spp isoladas em Goiânia de pacientes com clínica de aborto repetitivo. Rev.Pat.Trop. 23(1):45-59, jan./jun.1994.

A Gentamicina também mostrou-se bastante ativa, pois as CMIs para todas as Listeria spp estavam ( $\leq 5,0 \mathrm{ug} / \mathrm{ml}$ ), variando de $0,4-0,5 \mathrm{ug} / \mathrm{ml}$. As Listeria monocytogenes com sorotipos diferentes apresentaram as CMIs na faixa sensível variando de 0,4 - 4,0 ug/ml (Tabela 2, Gráfico 2).

As CMIs quantitativas da Penicilina estavam dentro da média, considerando sensível com todas as Listeria $\operatorname{spp}(\leq 2,0 \mathrm{ug} / \mathrm{ml})$, exceto duas que se mostraram intermediárias, variando de 3,0 a $3,4 \mathrm{ug} / \mathrm{ml}$ (Tabela 4, Gráfico 4).

Tabela 1 - Atividade da Ciprofloxacina entre as Listeria spp. Concentração Mínima Inibitória (CMI) e Concentração Minima Bactericida (CMB)

\begin{tabular}{c|c|c|c|c}
\hline CEPA & $\begin{array}{c}\text { CMI } \\
\text { quantitativa } \\
(\mu \mathrm{g} / \mathrm{ml})\end{array}$ & $\begin{array}{c}\text { CMI } \\
\text { qualitativa } \\
(\mu \mathrm{g} / \mathrm{ml})\end{array}$ & $\begin{array}{c}\text { CMB } \\
\text { quantitativa } \\
(\mu \mathrm{g} / \mathrm{ml})\end{array}$ & CMB/CMI \\
\hline 04 & 0,7 & 0,6 & 1,4 & 2,0 \\
23 & 0,9 & 1,2 & 1,8 & 2,0 \\
45 & 0,9 & 0,6 & 1,8 & 2,0 \\
54 & 0,8 & 0,6 & 2,0 & 2,5 \\
132 & 1,0 & 2,0 & 2,0 & 2,0 \\
143 & 0,5 & 0,6 & 1,9 & 3,0 \\
149 & 5,0 & 5,0 & 2,0 & 1,2 \\
181 & 0,8 & 0,6 & 2,0 & 2,5 \\
199 & 0,7 & 1,6 & 1,8 & 2,8 \\
L.m (A) & 0,7 & 0,6 & 1,5 & 3,0 \\
S.aureus & 0,5 & 0,6 & 0,0 & 1,5 \\
D. aerug & 0,6 & 0,01 & & 2,0 \\
E. celi & 0,01 & \multicolumn{4}{c}{} \\
\hline
\end{tabular}

CMI = Concentraça mínima inibitória

CMB = Concentração mínima bactericida

$04=$ Listeria gravi

23 = Listeria monocytogenes $1 / 2 \mathrm{a}$

$45=$ Listeria monocytagenes $4 \mathrm{~b}$

54 = Listeria monocytogenes $4 \mathrm{~b}$

132 = Listeria monecytogenes $1 / 2 \mathrm{a}$

143 = Listeria monocytozenes $1 / 2 a$

149 = Listeria gravi

181 = Listeria innocua $6 a$

199 = Listeria innocua não tipáve

L.m $(A)=$ Listeria monocytogenes $($ Scotta $A)$

S. aureus $=$ Staphyloceccus aureus ATCC 25923

P. aerug. = Pseudomonas seruginosa ATCC 27853

E. celi = Escherichis celi ATCC 25922
NOJIMOTO,I.T.I.;CENTENO,A.J.:YANAGUITA,R.M.;WATANABE,K.;KAKUMOTO,M.:MACHADO,R.M. Efeitos bacteriostáticos e bactericida de antibióticos sobre as Listeria spp isoladas em Goiânia de pacientes com clínica de aborto repetitivo. Rev.Pat.Trop. 23(1):45-59, jan./jun.1994.

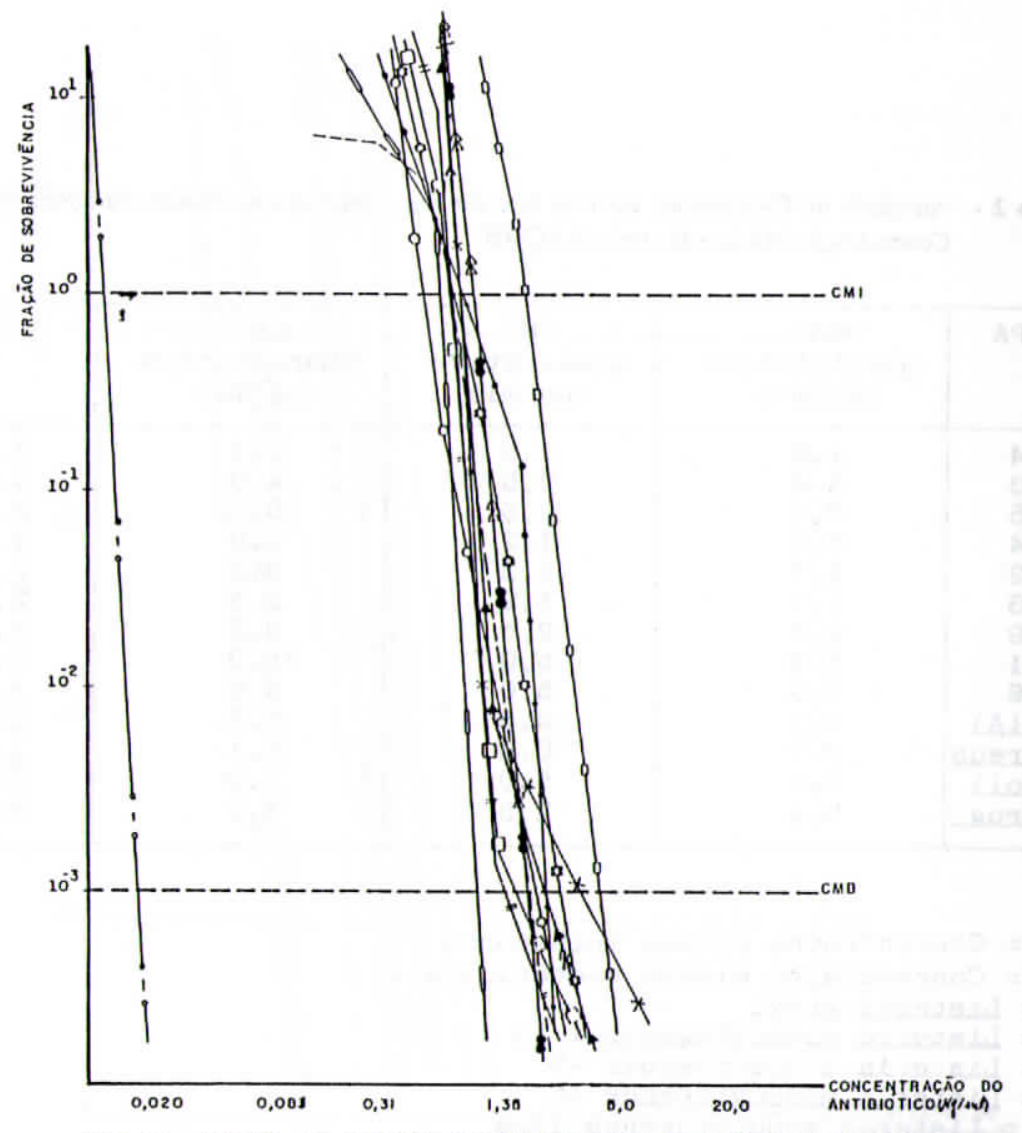

FIG. 01 - EFEITO DA CIPROFLOXACINA NA SOBREVIVÊNCIA DA LIsteria spp (CONCENTRAÇĀO MÍNIMA INIBITÓRIA E MÍNIMA BACTERICIDA)
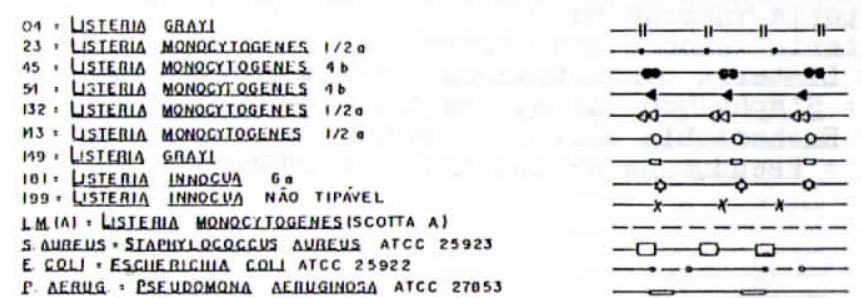
NOIMOTOIT I CENTENOA J.YANAGUTTA.R M:WATANABE,K:KAKUMOTO.M:MACHADO,R.M. Efeitos bacteriostáticos e bactericida de antibióticos sobre as Listeria spp isoladas em Goiânia de pacientes com clínica de aborto repetitivo. Rev.Pat.Trop. 23(1):45-59, jan./jun.1994.

Tabela 2 - Atividade da Gentamicina entre as Listeria spp. Concentração Mínima Inibitória (CMI) e Concentraçâo Mínima Bactericida (CMB)

\begin{tabular}{|c|c|c|c|c|}
\hline CEPA & $\begin{array}{c}\text { CMI } \\
\text { quantitativa } \\
\left(\mu_{\mathrm{B} / \mathrm{ml})}\right.\end{array}$ & $\begin{array}{c}\text { CMI } \\
\text { qualitativa } \\
(\mu \mathrm{g} / \mathrm{ml})\end{array}$ & $\begin{array}{c}\text { CMB } \\
\text { quantitativa } \\
(\mu \mathrm{g} / \mathrm{ml})\end{array}$ & $\mathrm{CMB} / \mathrm{CMI}$ \\
\hline $\begin{array}{c}04 \\
23 \\
45 \\
54 \\
132 \\
143 \\
149 \\
181 \\
199 \\
\text { Lm (A) } \\
\text { adreus } \\
\text { 2. coli } \\
\text { 2. aerug. }\end{array}$ & $\begin{array}{l}1,6 \\
4,0 \\
0,4 \\
0,6 \\
1,7 \\
1,7 \\
2,8 \\
5,0 \\
3,0 \\
0,7 \\
0,7 \\
3,4 \\
2,1\end{array}$ & $\begin{array}{l}2,5 \\
2,5 \\
0,6 \\
1,2 \\
1,2 \\
1,2 \\
2,5 \\
5,0 \\
5,0 \\
0,6 \\
0,6 \\
5,0 \\
2,5\end{array}$ & $\begin{array}{r}2,4 \\
4,0 \\
0,9 \\
0,9 \\
3,8 \\
3,5 \\
3,8 \\
15,0 \\
4,0 \\
2,5 \\
1,1 \\
7,0 \\
4,7\end{array}$ & $\begin{array}{l}1,5 \\
1,0 \\
2,2 \\
1,5 \\
2,2 \\
2,0 \\
1,0 \\
3,0 \\
1,3 \\
3,0 \\
1,5 \\
2,0 \\
2,2\end{array}$ \\
\hline
\end{tabular}

CMI = Concentraça mínima inibitória

$\mathrm{CMB}=$ Concentração mínima bactericida

04 = Listeria gravi

23 = Listeria menecytosenes $1 / 2$ a

$45=$ Listeria monocytogenes $4 \mathrm{~b}$

$54=$ Listeria monocytogenes $4 \mathrm{~b}$

$132=$ Listeria monocytogenes $1 / 2 a$

$143=$ Listeria monocytogenes $1 / 28$

$149=$ Listeria gravi

$181=$ Listeria gravi

$181=$ Listeria innocua $6 a$

19) = Listeria monocytogenes (Scotta A)

S.

.

P. aerue = Pseudomon aeruginosa ATCC 27853
NOJIMOTOITI:CENTENOAJ:YANAGUITA R M : WATANABE,K:KAKUMOTO,M:MACHA DO,R.M. Efeitos bacteriostáticos e bactericida de antibióticos sobre as Listeria spp isoladas em Goiânia de pacientes com clínica de aborto repetitivo. Rev.Pat.Trop. 23(1):45-59, jan.jun.1994.

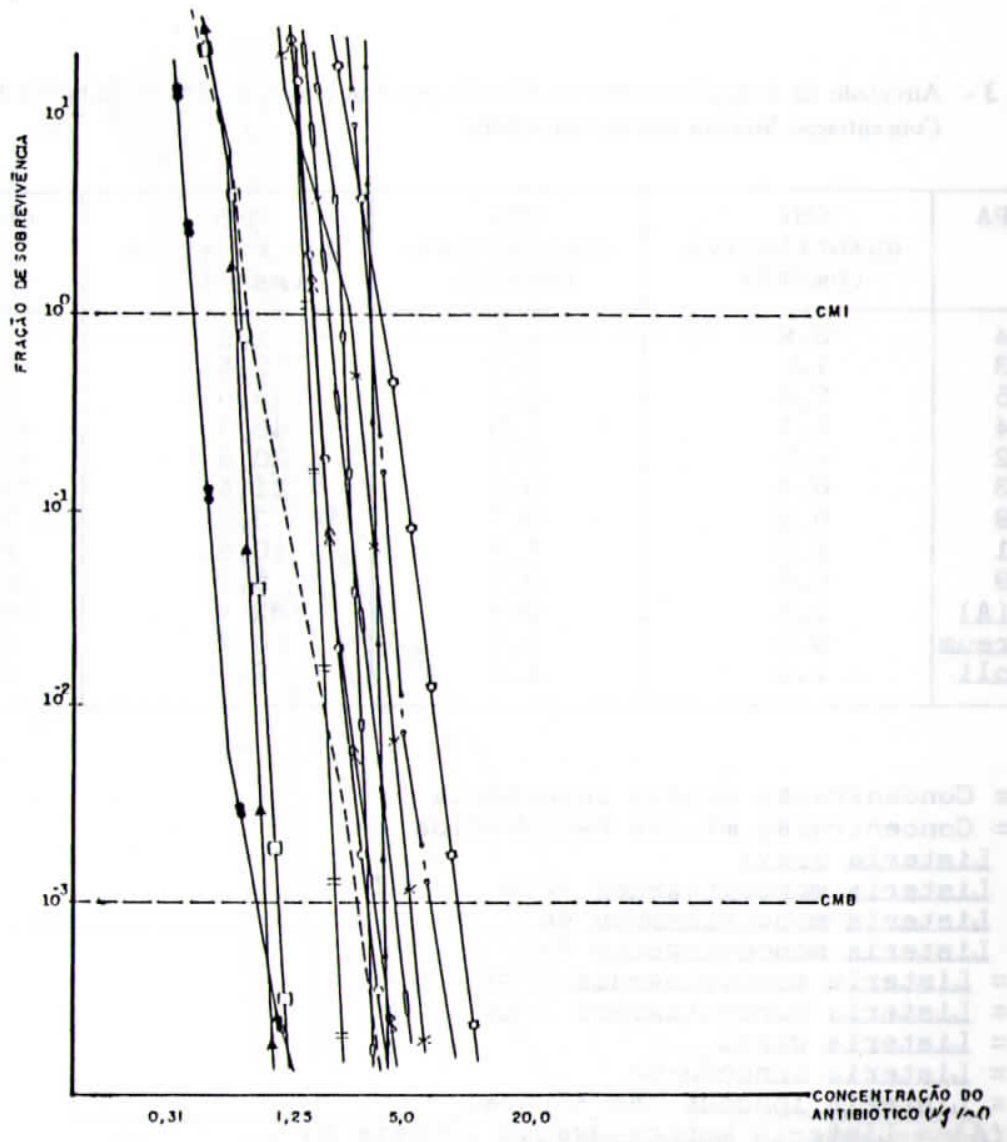

FIG. 02 - EFEITO DA GENTAMICINA NA SOBREVIVÊNCIA DA LIsteria spp (CONCENTRAÇÁO MÍNIMA INIBITÓRIA E MÍNIMA BACTERICIDA)

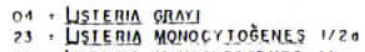

15. LISIERIA MOHOCYIOGENES 1

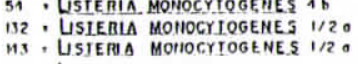

Ma . LSTERIA GRAYI

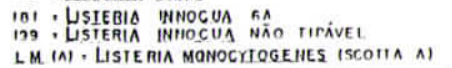

S. AUREUS - STARBKLOCOCGCUS AUREUS ATCC 25923

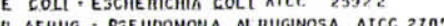

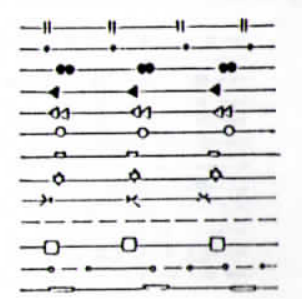


NOJIMOTO,I.T.I.;CENTENO,A.J.;YANAGUITA,R.M.;WATANABE,K.;KAKUMOTO,M.;MACHADO,R.M. Efeitos bacteriostáticos e bactericida de antibióticos sobre as Listeria spp isoladas em Goiânia de pacientes com clínica de aborto repetitivo. Rev.Pat.Trop. 23(1):45-59, jan./jun.1994.

Tabela 3 - Atividade da Ampicilina entre as Listeria spp. Concentraçāo Mínima Inibitória (CMI) e Concentraçāo Mínima Bactericida (CMB)

\begin{tabular}{c|c|c|c|c}
\hline CEPA & $\begin{array}{c}\text { CMI } \\
\text { quantitativa } \\
(\mu \mathrm{g} / \mathrm{ml})\end{array}$ & $\begin{array}{c}\text { CMI } \\
\text { qualitativa } \\
(\mu \mathrm{g} / \mathrm{ml})\end{array}$ & $\begin{array}{c}\text { CMB } \\
\text { quantitativa } \\
(\mu \mathrm{g} / \mathrm{ml})\end{array}$ & CMB/CMI \\
\hline 04 & 0,9 & 1,5 & 1,6 & 1,7 \\
23 & 1,0 & 3,1 & 2,5 & 2,5 \\
45 & 2,0 & 3,1 & 4,0 & 2,0 \\
54 & 1,1 & 1,5 & 46,0 & 41,8 \\
132 & 0,5 & 0,7 & 20,0 & 40,0 \\
143 & 0,4 & 0,3 & 11,5 & 28,7 \\
149 & 0,6 & 0,7 & 3,1 & 5,1 \\
181 & 1,2 & 1,5 & 10,5 & 8,7 \\
199 & 0,5 & 0,7 & 5,0 & 10,0 \\
L.m (A) & 1,1 & 0,7 & 32 & 26,8 \\
S.aureus & 0,3 & 1,5 & 2,7 & 2,1 \\
E. coli & 1,0 & & 2,0 & 1,0 \\
\hline
\end{tabular}

CMI = Concentraça mínima inibitória

CMB = Concentraçơ mínima bactericida

$04=$ Listeria grayi

23 = Listeria monocytogenes $1 / 2 a$

45 = Listeris monocytogenes $4 \mathrm{~b}$

54 = Listeria monocytogenes $4 \mathrm{~b}$

132 = Listeria monocytogenes $1 / 2 \mathrm{a}$

$143=$ Listeria monocytogenes $1 / 2 a$

149 = Listeria grayi

$181=$ Listeria innecus $6 a$

199 = Listeria innecua năo tipável

L.m $(A)=$ Listeria monocytogenes $($ Scotta $A)$

S. aureus = Staphylecoccus aureus ATCC 25923

E. coli = Escherichis coli ATCC 25922

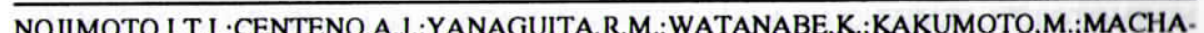
DO,R.M. Efeitos bacteriostáticos e bactericida de antibióticos sobre as Listeria spp isoladas em Goiânia de pacientes com clínica de aborto repetitivo. Rev.Pat.Trop. 23(1):45-59, jan./jun.1994.

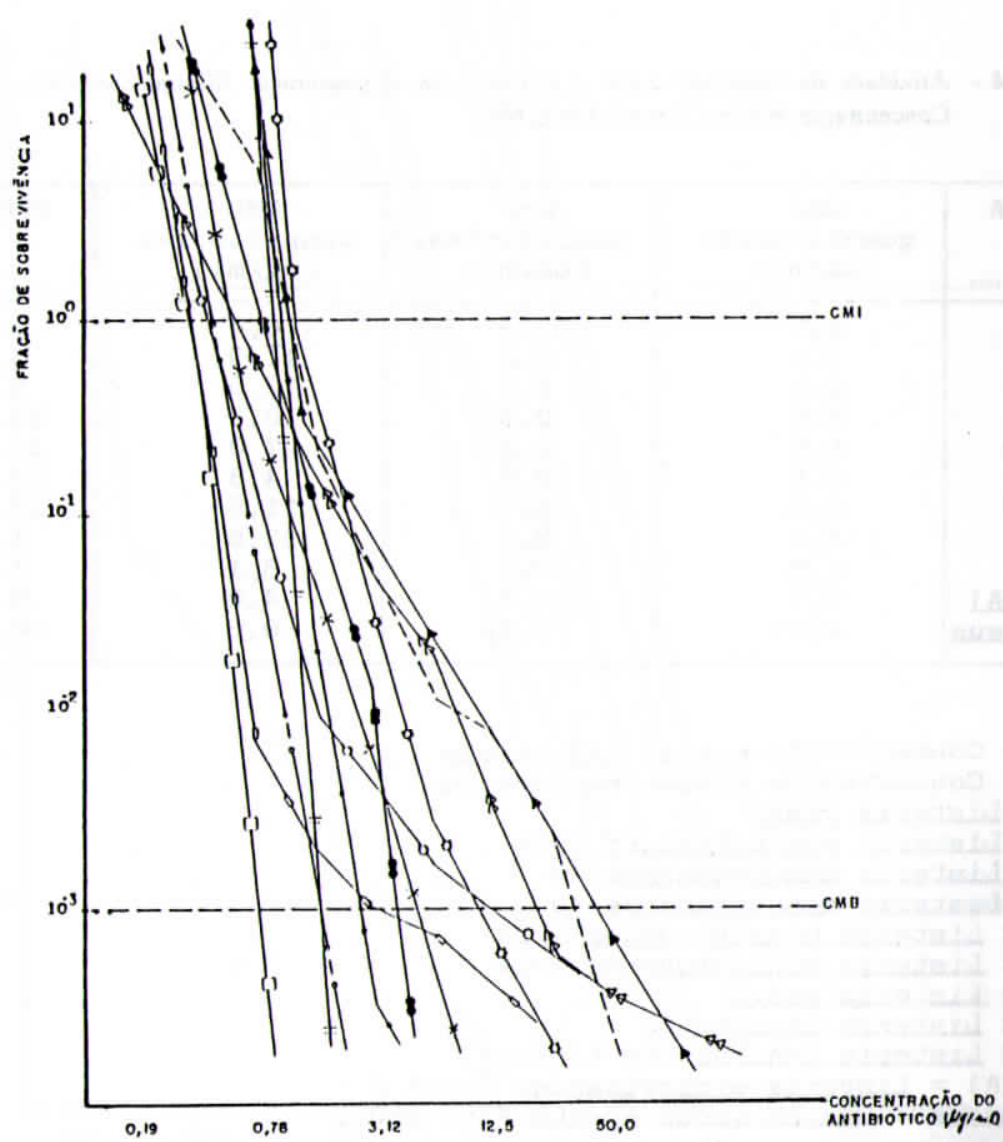

FIG 03 - EFEITO DA AMPUCILINA NA SOBREVIVÊNCIA DA LIsteria spp CONCENTRAÇÁO MÍNIMA INIBITÓRIA E MÍNIMA BACTERICIDA)

O1. : LSIE BIA GRAYL

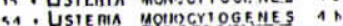

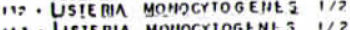

ii. . Ustemina gari

in! - Lisienis. introcus o.

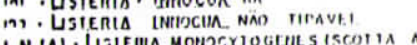

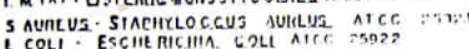

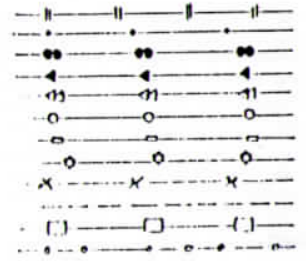


NOJIMOTO,I.T.I.:CENTENO,A.J.YYANAGUITA.R.M.:WATANABE.K.:KAKUMOTO,M.MACHADO,R.M. Efeitos bacteriostáticos e bactericida de antibióticos sobre as Listeria spp isoladas em Goiânia de pacientes com clínica de aborto repetitivo. Rev.Pat.Trop. 23(1):45-59, jan.jun.1994.

Tabela 4- Atividade da Penicilina entre as Listeria spp. Concentraçăo Mínima Inibitória (CMI) e Concentração Mínima Bactericida (CMB)

\begin{tabular}{c|c|c|c|c}
\hline CEPA & $\begin{array}{c}\text { CMI } \\
\text { quantitativa } \\
(\mu \mathrm{g} / \mathrm{ml})\end{array}$ & $\begin{array}{c}\text { CMI } \\
\text { qualitativa } \\
(\mu \mathrm{g} / \mathrm{ml})\end{array}$ & $\begin{array}{c}\text { CMB } \\
\text { quantitativa } \\
(\mu \mathrm{g} / \mathrm{ml})\end{array}$ & CMB/CMI \\
\hline 04 & 1,7 & 2,3 & 6,4 & 3,7 \\
23 & 3,4 & 6,2 & 11,0 & 3,2 \\
45 & 2,0 & 1,5 & 12,0 & 6,0 \\
54 & 0,5 & 0,3 & 16,0 & 32,0 \\
132 & 0,6 & 0,3 & 7,0 & 11,6 \\
143 & 0,4 & 0,7 & 4,8 & 12,0 \\
149 & 0,5 & 0,7 & 11,0 & 22,0 \\
181 & 3,0 & 3,1 & 12,5 & 4,1 \\
199 & 1,8 & 3,1 & 3,1 & 1,7 \\
L.m (A) & 0,7 & 0,7 & 4,8 & 6,4 \\
S.aureus & 0,01 & 0,02 & 0,3 & 30,0 \\
\hline
\end{tabular}

CMI = Concentraçăo mínima inibitória

CMB = Concentração mínima bactericida

$04=$ Listeria gravi

$23=$ Listeria monocytogenes $1 / 2 a$

45 = Listeria monocytogenes $4 b$

$54=$ Listeria menoevtegenes $4 b$

132 = Listeria monocytogenes $1 / 2 a$

143 = Listeria monocytogenes $1 / 2 a$

$149=$ Listeria grayi

$181=$ Listeris innecua $6 a$

199 = Listerla innecua não tipável

S. aureus = Staphyleccus aureus ATCC 25923
NOIMOTOITI:CENTENOA.J.YANAGUITA R M.WATANABE.K:KAKUMOTO.M :MACHA DO,R.M. Efeitos bacteriostáticos e bactericida de antibióticos sobre as Listeria spp isoladas em Goiânia de pacientes com clínica de aborto repetitivo. Rev.Pat.Trop. 23(1):45-59, jan./jun.1994.

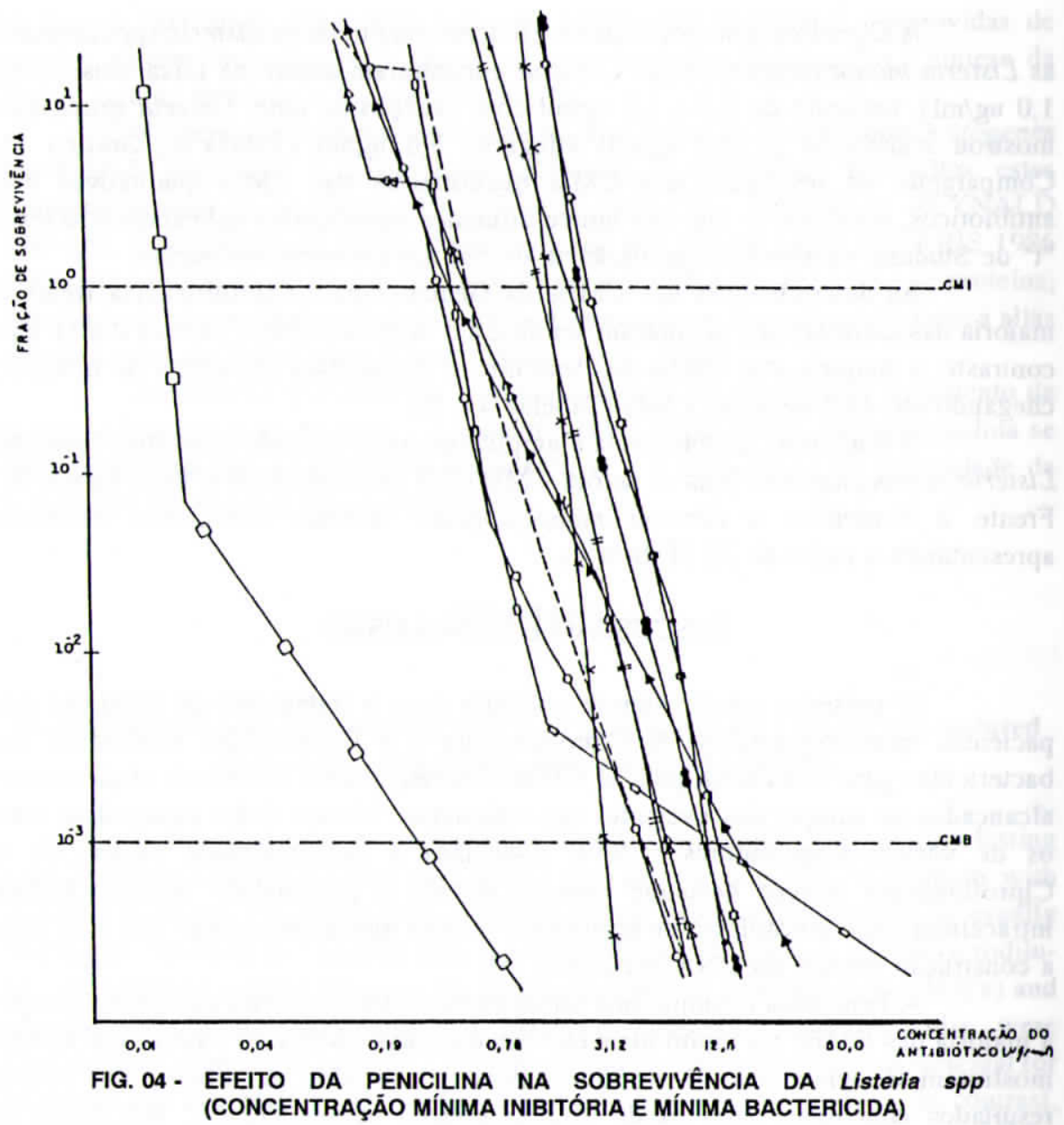

$04:$ USIERA GARTI

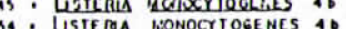

132. USIERIA MOHQCTROGLUES $1 / 2$ 。

19. Lusrema gianter

101. USTERIA IAHOCUA 6A

LA IAI. LSIEHWA HOHOCTOGEMES ISCOT TA AI

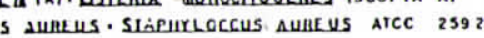

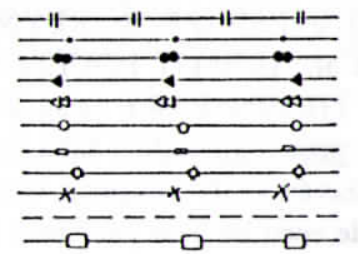


NOIMOTO,I.T.I.CENTENO,A.J.YYANAGUITA,R.M.;WATANABE K.KAKUMOTO,M.MACHADO,R.M. Efeitos bacteriostáticos e bactericida de antibióticos sobre as Listeria spp isoladas em Goiânia de pacientes com clínica de aborto repetitivo. Rev.Pat.Trop. 23(1):45-59, jan.jun.1994

A Ciprofloxacina foi bastante eficiente para todas as Listeria spp inclusive as Listeria monocytogenes, cujas CMIs se encontraram dentro da faixa sensível $<<$ $1,0 \mathrm{ug} / \mathrm{ml})$, variando de 0,5 a $1,0 \mathrm{ug} / \mathrm{ml} \mathrm{com}$ exceção de uma, Listeria grayi, que mostrou resistência (> 4,0 ug/ml) atingindo $5,0 \mathrm{ug} / \mathrm{ml}$ (Tabela 1, Gráfico 1). Comparando os resultados das CMIs quantitativas das CMIs qualitativas dos antibióticos, verificou-se que não houve diferença significativa aplicando-se o teste " $\mathrm{t}$ " de Student, no nível de significância de $5 \%$ nas amostras analisadas.

As determinaçōes das CMBs da Gentamicina e Ciprofloxacina frente maioria das Listerias spp mostraram ser de 2 a 3 vezes as CMIs (Tabelas 2 e 1). Em contraste, a maioria das CMBs de Penicilina e Ampicilina foi acima de 6 vezes, chegando até 41,8 vezes as CMIs (Tabelas 4 e 3).

$\mathrm{O}$ fenômeno da tolerância à ampicilina foi constatado com duas cepas de Listeria monocytogenes, pois as razões CMB/CMI foram de 41,8 e 40,0 (Tabela 3). Frente à Penicilina a Listeria monocytogenes também mostrou-se tolerante apresentando a razão de 32 (Tabela 4).

\section{DISCUSSĀO E CONCLUSÃO}

O presente estudo oferece subsídio para o tratamento de listeriose em pacientes imunodeprimidos. A Ciprofloxacina e a Gentamicina mostraram ser bactericidas para as Listeria pois as CMBs estavam dentro dos níveis clinicamente alcançados no sangue dos pacientes em tratamento. Nossos dados concordam com os de vírios pesquisadores $(5,8,9)$. Associada à potencialidade bactericida a Ciprofloxacina merece destaque especial devido à propriedade farmacocinética intraceluar, cujo mecanismo de ação se faz junto à girase, impedindo que esta, faça a constrư̧ão normal do DNA bacteriano (5).

A Penicilina e Ampicilina foram bacteriostáticas contra as Listeria porque a maioria das CMBs foi muito mais elevada que suas CMIs e os valores das CMBs mostraran-se acima dos níveis clinicamente alcançados na terapia. Os nossos resultado: concordam com os de MOELLERING et al.,1972 (9), WIGGINS e al.,1978 (13) e ESPAZE \& REYNAUD 1988 (6), porém discordam dos de GORDON et al., 1970 (7), POULSEN et al.,1988 (10), que afirmam que elas são bactericicas. THORNSERRY et al.,1970 (12) esclareceram que estas contradições estão ligadas principalmente à falta de padronização de metodologia.

Através desta pesquisa verifica-se que a Penicilina e a Ampicilina são antibióticss de escolha para pacientes nâo imunocomprometidos. Esse fator positivo
NOJIMOTO,I.T.I.;CENTENO,A.J.;YANAGUITA,R.M.;WATANABE,K.;KAKUMOTO,M.;MACHA DO,R.M. Efeitos bacteriostáticos e bactericida de antibióticos sobre as Listeria spp isoladas em Goiânia de pacientes com clínica de aborto repetitivo. Rev.Pat.Trop. 23(1):45-59, jan./jun.1994.

se deve à toxicidade quase nula sobre as células dos mamíferos desprovidas de paredes, porém biologicamente ativas sobre as bactérias, bloqueando a síntese da parede celular, inibindo a transpeptidação (8).

No presente trabalho encontrou-se uma cepa de Listeria monocytogenes tolerante à penicilina $\mathrm{e}$ duas cepas tolerantes à ampicilina, resultados estes compatíveis com os de MOELLERING et al.,1972 (9) e ESPAZE \& REYNALD 1988 (6). O fenômeno de tolerância é explicado por autores como SHERRIS 1986 (11), como resultado de uma inibição secundária de RNA ou de síntese de proteína, induzindo um aumento de sobreviventes de algumas cepas quando submetidas a altas concentraçōes de antibiótivos B lactâmicos.

Acredita-se que uma das causas das falhas terapêticas do tratamento da listeriose humana com os mais comumente usados antibióticos, como penicilina se deva provavelmente ao fenômeno de tolerância e à ineficiência da capacidade da penetração intracelular desses antibióticos.

\section{SUMMARY}

Bacteriostatics and bactericidal effects of antibiotics on Listeria spp isolated in Goiania of patients with repeated abortion

In this study were examined the "in vitro" antibiotic susceptibility testing against recent clinical isolated of Listeria spp from endocervix of womem with repeated abortion. Treatment with antibiotics most often recommended, is usually successful, but there are several case reports descriting faillure. A broth macrodilution method was used to measure the minimal inhibitory concentrations (MICs) and minimal bactericidal concentrations (MBCs). Ampicillin and penicillin were bacteriostatic against Listeria spp. Gentamicin and ciprofloxacin were bactericidal for all the strains and MBCs were within 3 fold dilutions above the MICs. In contrast, the MBCs for penicillin and ampicillin were at least 6 fold dilutions above the MICs. Three isolates of Listeria monocytogenes showed tolerance to penicillin and ampicillin.

KEYWORDS: Antibiotics, Macrodilution, Listeria spp. Repeated abortation 


\section{REFERÊNCIAS BIBLIOGRÁFICAS}

01. AUCKENTHALER,R.; MICHÉA-HAMZEPHPOUR,M. \& PECHÉRE,J.C.In vitro activith of new quinolones against aerobic bacteria. J.Antimicrob. Chemother,17: suppl.B,29-39,1986.

02. BERCHE,P.; GAILLARD,J.L.; RICHARD,S. Invasiveness and intracellular growth of Listeria monocytogenes. Infection,16 suppl.2: S145-S148., 1988.

03. BOJSEN-MOLLER,J. Human listerioses: diagnostic, epidemiologic and clinical studies. Acta Pathol. Microbiol.Scand. Sect. B Suppl.,229:721-30,1972.

04. BUCHNER,L.H. \& SCHNEIRSON,S.S. Clinical and laboratory aspects of Listeria monocytogenes infections with a report of ten cases. Amer.J.Med.,45:904-21,1968.

05. EASMON,C.S.F.; CRANE,J.P. \& BLOWERS,A. Effect of ciprofloxacin on intracellular organisms: in vitro and in vivo studies. J. Antimicrob. Chemother,18: 43-48,1986.

06. ESPAZE,E.P. \& REYNAUD,A.E. Antibiotic susceptibilities of Listeria: "in vitro" studies. Infection, 16: 160-4,1988.

07. GORDON,R.C.; BARRET,F.F.; YOW,M.D. Ampilicin treatment of listeriosis. J.Pediatr., 7:1067-70,1970.

08. HOF,H. Therapeutic activities of antiobiotics in Listeriosis. Infection,19:219 223,1991 .

09. MOELLERING,R.C.; MEDOFFG; LEECH,I. Antibiotic synergism against Listeria monocytogenes. Antimicrob. Agents Chemother.,1:30-34,1972.

10. POULSEN,P.N.; CARVAJAL,A.; LESTER,A. \& ANDREASEN,J. In vitro susceptibility of Listeria monocytogenes isolated from human blood and crebrospinal fluid during the years 1958 - 1985. APMIS,96:223-8,1988.
NOJIMOTO,I.T.I.;CENTENO,A.J.;YANAGUITA,R.M.;WATANABE,K.;KAKUMOTO,M.;MACHADO,R.M. Efeitos bacteriostáticos e bactericida de antibióticos sobre as Listeria spp isoladas em Goiânia de pacientes com clínica de aborto repetitivo. Rev.Pat.Trop. 23(1):45-59, jan./jun.1994.

11. SHERRIS,J.C. Problems in "in vitro" determination of antibiotic tolerance in clinical isolates. Antimicrob. Agentes Chemother.,30:633-37,1986.

12. THORNSBERRY,C.; BAKER,C.M.; FACKLAM,R.R. Antibiotic susceptibility of Streptococcus bovis and other group D streptococci causing endocarditis. Antimicrob. Agents Chemother.,5:228-33,1978.

13. WIGGINS,G.L.; ALBRITTON,W.L.; FEELEY,J.C. Antibiotic susceptibility of clinical isolates of Listeria monocytogenes. Antimicrob. Agents Chemother.,13: 854-60,1978. 